\title{
ComunidDADES DE CONVERSACión: \\ la construcción de los casos jurídico y personal en un consultorio jurídico rural
}

\author{
Silvia Monroy Álvarez \\ Universidad de Antioquia, departamento de antropología \\ silviamonroy@hotmail.com \\ Carolina Llanes Guardiola \\ UNIVERSIDAD DE ANTIOQUIA \\ ninallag@hotmail.com
}

\begin{abstract}
Resumen
[ STE ARTÍCULO PRESENTA UN EXPERIMENTO ETNOGRÁFICO EN EL CONSULTORIO JURÍDICO [ rural del municipio de Fredonia (departamento de Antioquia). Analiza cómo abogado y consultante crean su caso, jurídico y personal. Se trabajan la construcción del caso por parte del abogado y su creación por parte de los usuarios. En la elaboración de la historia personal se destacan tres características: se construye a la par de la traducción del practicante; se da especial importancia a la narración cronológica de los hechos; y está ligada a un performance. En suma, se hará evidente el choque de dos formas de representación: la de los practicantes, basada en un saber especializado, y la de los usuarios, fundamentada en estrategias que derivan de lógicas locales.

PALABRAS ClAVE: antropología jurídica, consultorio jurídico, Antioquia, campesinos, comunidades de conversación.
\end{abstract}

\section{Abstract}

T HIS ARTICLE PRESENTS AN ETHNOGRAPHICAL EXPERIMENT CARRIED OUT IN THE LEGAL ASIStance office in Fredonia (Antioquia). It analyses how the law student and the client create their own cases, both juridical and personal. The text focuses on the construction of the legal case, which shows how the lawyer produces the facts, and the creation of a personal case by clients. The process has three main characteristics: the personal story and the lawyer's translation are both constructed simultaneously; the chronological narration of facts is especially important, and it involves a performance. In short, the article illustrates the clash between two forms of representation: the lawyer's, based on specific knowledge, and the client's, based on local strategies.

KEY wORDS: Legal Anthropology, law assistance office, Antioquia, peasants, conversation communities.

Revista Colombiana de Antropología

Volumen 4I, enero-diciembre 2005, pp. 75-106 


\section{INTRODUCCIÓN}

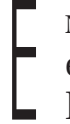
N ESTE ARTÍCULO SE ANALIZA PARTE DE LA INFORMACIÓN OBTENIDA EN el proyecto "El consultorio jurídico y los nuevos espacios para la exploración en la etnografía”", que se proponía establecer una serie de "comunidades de conversación” en Fredonia, un municipio cercano a la ciudad de Medellín, en el espacio destinado a que los estudiantes de último año de derecho hicieran su práctica en una zona rural del departamento ${ }^{2}$.

El objetivo principal era explorar y analizar las posibilidades metodológicas de la etnografía en el consultorio jurídico de Fredonia, por medio de las “comunidades de conversación”. Trabajado por Gudeman y Rivera (I990) entre grupos campesinos, este concepto se refiere a unidades que permiten diálogos entre sujetos pertenecientes a diferentes

I. El proyecto ganó la convocatoria del Comité para el desarrollo de la investigación (Codi) de la Universidad de Antioquia (Medellín), para proyectos de menor cuantía; la investigación duró ocho meses, entre octubre de 2003 y junio de 2004 , y fue radicada en el Centro de investigaciones de ciencias sociales y humanas (CISH). La propuesta recibió también el apoyo del Observatorio del estado y la alteridad sociojurídica, célula adscrita al Grupo de investigación cultura, política y desarrollo social de la Universidad de Antioquia, reconocido por Colciencias.

2. El grupo asignado a Fredonia está compuesto por seis estudiantes -cuatro mujeres y dos hombres-que deben recibir la consulta jurídica durante el tiempo equivalente a dos semestres académicos; el equipo es coordinado y asesorado por un abogado titulado con veinte años de experiencia que, no obstante, nunca ha sido docente formal. Sólo se llevan casos de residentes en Fredonia que puedan comprobar -mediante recibos de agua, energía e impuesto predial-que pertenecen a estratos bajos y, por tanto, no pueden pagar un abogado. Los estudiantes atienden en la Casa de la cultura del municipio el domingo, día de mercado, cuando los pobladores de las veredas se desplazan al casco urbano. Aun cuando se atiende un promedio de treinta personas, muchas de las consultas no se convierten en negocio, en palabras de los abogados. El practicante recibe la consulta y emite un concepto inicial que luego se debate en una reunión del grupo con el asesor; allí se decide si el caso puede ser llevado y, de ser así, se le asigna a algún practicante. grupos sociales -y tradicionesya que se caracterizan por la ausencia de límites, que las valida como entidades que producen e impulsan espacios de discusión permanente. En las comunidades de conversación, los investigadores procuran no elaborar autoritariamente en el contexto del diálogo que suele ser espontáneo y abierto porque justamente se seleccionan contextos en los que se dan esos diálogos y no se recurre al esquema pregunta-respuesta que suele limitar la experiencia etnográfica. Lo anterior no quiere decir que sea un espacio libre de conflicto, puesto que allí se pueden mostrar, reforzar y desafiar también jerarquías sociales mediante el propio discurso y los mecanismos performativos ligados a él. Este es, justamente, el caso de la consulta jurídica. 


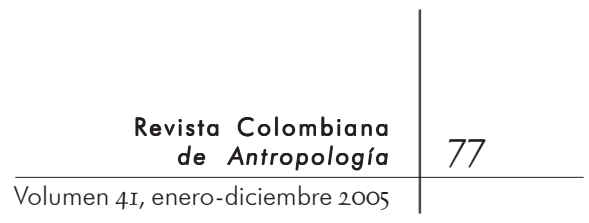

En el fondo, el propósito del proyecto era unir dos elementos: "comunidades de conversación" -metodología- y consultorio jurídico -microcosmos ${ }^{3}$-, en medio de un experimento antropológico que, teniendo en cuenta múltiples voces, pudiera plantear nuevas temáticas y preguntas de investigación. La fase de campo duró cuatro meses y el equipo de investigación, compuesto por tres etnógrafos, se desplazó a Fredonia los fines de semana, cuando los estudiantes de derecho acudían a atender a la comunidad. De esta manera, se establecieron varias "comunidades de conversación”, estando conformada la célula básica, que coincide con la consulta jurídica in situ, por el practicante de derecho, el etnógrafo y el consultante ${ }^{4}$. Coincidencialmente, las y los practicantes se desplazaban en grupos de tres personas, lo cual permitió que cada miembro del equipo de etnógrafos estuviera al tanto de las labores de cada practicante.

3. Jackson (1998) define estos microcosmos como contextos locales aparentemente reducidos (minima etnographica) que se convierten en universos complejos gracias al poder que se le asigna al Además de la "comunidad diálogo y, a partir de él, a las historias de vida. de conversación básica”, otros 4. Nos referiremos al etnógrafo en singular al espacios se consideraron " $\mathrm{CO}$ - hablar del sujeto involucrado en la célula básica; y hablaremos de los etnógrafos para referirnos más munidades de conversación”, a situaciones particulares del trabajo de campo. como las reuniones de los prac- De igual manera, al hablar de los abogados estaremos haciendo referencia a los practicantes de úlentre el grupo de etnógrafos, repeticiones que tornen pesada la lectura.

en las que evaluaban los avances de la investigación; las conversaciones con los directivos y asesores del consultorio jurídico en Medellín; los diálogos de la "comunidad de conversación académica”, integrada por algunos miembros del Observatorio del estado y la alteridad sociojurídica, grupo de investigación que apoyó la iniciativa; y los diálogos sostenidos con algunos de los consultantes en el municipio, considerados y denominados "conversaciones ampliadas", ya que dependieron siempre de la célula básica. De hecho, los resultados que se presentan se refieren en mayor medida a la información recolectada en el contexto de la célula básica, contenida en dos formatos estructurados durante el transcurso del proyecto: las fichas de reunión, en las que los etnógrafos consignaban la información de las reuniones de los practicantes con su asesor; y los diarios de campo, elaborados visita a visita por los tres etnógrafos. Esto además de la transcripción de las grabaciones hechas en el marco de las 
"comunidades de conversación". Se tuvieron en cuenta también los informes y documentos elaborados por los abogados: actas de reuniones e informes de las salidas.

En el artículo se busca mostrar cómo construyen su caso el practicante de derecho y el consultante, involucrados en la "comunidad de conversación" in situ. No obstante, es necesario mostrar antes cómo entraron los etnógrafos en dicha "comunidad de conversación” para ver la dinámica de la célula básica y para entender cómo se obtuvo la información utilizada para analizar la construcción de los tipos de casos -los elementos que facilitaron y los que limitaron el ejercicio de exégesis-. Después de este apartado, se examina la construcción del caso jurídico por parte de los abogados, para identificar luego las características principales de la construcción del caso personal por parte de los consultantes. De lo que se trata es de hacer evidente el choque de lógicas que se da entre practicantes y usuarios, que remite a una puesta en escena de dos formas de representación: la de los estudiantes de derecho, centrada en un lenguaje especializado propio de un saber experto, y la de los consultantes, fundamentada en estrategias que derivan de lógicas locales, pero que apunta hacia la búsqueda de reconocimiento de los actores implicados en su compleja identidad social.

EL FUNCIONAMIENTO DE LAS

"COMUNIDADES DE CONVERSACIÓN" IN SITU

OMO SE Dijo, El ETNógrafo hizo PARTE DE LA “COMUnidAd DE conversación” durante la consulta jurídica, lo cual le permitió participar en el proceso de traducción que hacía el practicante. En muchos casos, procuró traducir al abogado las preguntas que formulaban los usuarios, en las que muchos de ellos intentaban usar términos jurídicos, errados desde la perspectiva de los estudiantes de derecho. Algunos, por ejemplo, hablaban del salario mínimo para referirse a la cuota de alimentos, otros confundían una tutela con una demanda y, en ocasiones, se referían al divorcio para hablar de sucesiones, etcétera. Dentro de su manejo escaso de la terminología jurídica, los etnógrafos hacían las aclaraciones a los practicantes, pero era evidente que estos parecían sentirse más cómodos cuando las hacían 


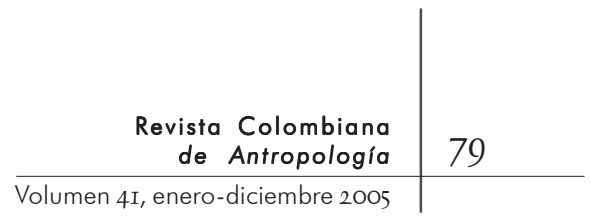

sus compañeros. Sin embargo, las aclaraciones fundamentales que hacían los etnógrafos recordaban a los practicantes lo narrado por los consultantes en las sesiones anteriores.

Los practicantes buscaban -o aceptaban- la ayuda de los etnógrafos durante los momentos de la conversación en los que los usuarios no estaban presentes: al comienzo o final de la sesión de consulta. A la postre, esas conversaciones abrieron nuevos caminos a la interpretación etnográfica, pues los etnógrafos pudieron presenciar así la transcripción personal que los abogados hacían de los casos. De todas formas, estos no dejaron de asumir la presencia del etnógrafo como una especie de amenaza; pero, así mismo, el desconocimiento del lenguaje jurídico hacía también que se desafiara la superioridad tradicional del observador frente a los otros.

En muchas ocasiones, sobre todo cuando los abogados hablaban durante buena parte de la conversación para explicar el procedimiento por seguir, los usuarios y los etnógrafos quedaban al margen, sin que pudieran responder ni preguntar cuestiones que se postulaban para no dejar lugar a las dudas. Lo anterior permitía también establecer un lazo de solidaridad entre los dos, aun cuando los etnógrafos tuvieron dificultades para explicar los objetivos de la investigación. Por otra parte, muestra el dilema del etnógrafo: hacer lo posible por estar en una posición intermedia entre ser totalmente participante o totalmente observador, aun cuando fluctuando entre tener un lugar como participante-observador y otro como observador-participante (Hammersley y Atkinson,I994). Lo más importante en esa búsqueda de posición es la construcción de una relación con esos sujetos que le permita, en últimas, acceder a una experiencia más amplia del otro: entrar en su vida y conocer lo que puede estar detrás del hecho -en este caso en particular- de haber acudido a un espacio jurídico. Irremediablemente, los usuarios relacionaban al etnógrafo con los abogados, y este fue uno de los hechos que más influyó durante las sesiones ampliadas ${ }^{5}$. Bastantes usuarios aceptaron que el equipo de etnógrafos fuera a sus casas para continuar charlando sobre la historia que estaba tras la consulta jurídica. El motivo de la consulta y del proceso jurídico fueron la

5. Así se denominaron las conversaciones de los etnógrafos con algunos de los usuarios del Consultorio jurídico en ausencia de los abogados. En su mayoría, se tuvieron en la casa de los consultantes y no se consideraron una "comunidad de conversación" independiente, sino una muy ligada a la célula básica de la consulta in situ. 
excusa perfecta para darle prioridad al relato de los consultantes e intentar oír, con menos pausas que las hechas por el abogado, la construcción del caso personal. Esto se consiguió en buena parte, pero durante las conversaciones los usuarios buscaban que los etnógrafos les resolvieran dudas jurídicas que estos no podían solucionar, creándose así barreras momentáneas en la comunicación; en otros casos, buena parte de los temores y quejas en relación con el tratamiento recibido en el Consultorio se eliminaban de los diálogos, en vista de que se asimilaban a una extensión de la consulta.

En el transcurso de esas conversaciones extendidas o ampliadas, los etnógrafos debieron acudir también a una especie de mapa sobre los detalles del caso expuesto por el consultante. Mientras el abogado lo construía por medio de la información fragmentada suministrada por los consultantes en cada visita -fragmentada en la medida en que ellos iban filtrando los datos de acuerdo con el procedimiento que consideraban idóneo-, el etnógrafo recogía la mayor cantidad de información posible a la espera de indagar en una multiplicidad de aspectos enunciados por el consultante sin orden establecido. El oír del etnógrafo fue desafiado porque el practicante procuraba detentar el control en buena parte de las conversaciones; y, además, por los mismos esquemas de construcción del caso personal utilizados por los consultantes. Cardoso de Oliveira (2004) habla del empobrecimiento de la función del acto cognitivo presente en el oír cuando las preguntas del etnógrafo -como él especifica- son precisas y sólo van en una dirección, haciendo surgir un campo ilusorio de interacción, lejos de una relación dialógica. Lo ocurrido durante la "comunidad de conversación" básica es coherente con la propuesta del autor de transformar ese "informante" en un interlocutor, con el fin de propiciar un encuentro etnográfico en el que se fundan los horizontes de los involucrados, lo cual -en otras palabras- es una de las características definidas por Gudeman y Rivera (I990) en relación con las comunidades de conversación: la exploración de espacios de conversación en los cuales la interacción guíe las preguntas, afirmaciones y propuestas de los participantes. Además, es preciso tener en cuenta que la "comunidad de conversación" in situ -o consulta jurídica-implica un performance de las partes involucradas y, por ello, la construcción de los casos debe entenderse también como la de una representación. 


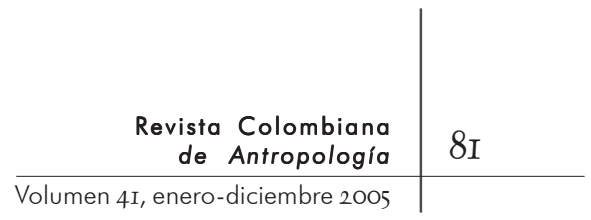

\section{LA CREACIÓN DEL CASO JURÍDICO}

ARA ENTENDER LA CONSTRUCCIÓN DEL CASO JURÍDICO COMO REPRESENtación es necesario profundizar en tres aspectos básicos: I) los efectos del lenguaje especializado del derecho que dan cuenta de su carácter de saber experto; 2) el papel del abogado como traductor; y 3) la representación pública del abogado por medio de una puesta en escena elaborada.

Geertz (1994) señala que la explosión de los hechos, el temor a los mismos y su esterilización es una característica de la práctica actual del derecho y de la reflexión sobre este. De ahí que pueda decirse que el derecho configura hechos que, a su vez, conforman diagramas cerrados de realidad que producen un proceso de equivalencias por medio de un lenguaje especializado. Entonces, el derecho, como todas las disciplinas, propone un marco en el que tengan sentido sus propias descripciones. Por esta razón, Geertz afirma que es una manera de imaginar lo real, más allá de un conjunto de normas, reglas, principios y valores.

Aun cuando durante los cuatro meses de trabajo de campo se siguieron varios casos sin que se tomara una decisión judicial, se pudo ver una porción significativa del proceso de construcción de casos jurídicos, en el que se evidencian todos los juegos del lenguaje que permiten entender que su preparación no es sólo la presentación de pruebas en apoyo a un aspecto determinado, sino que implica el tránsito del lenguaje de la imaginación al de la decisión; se trata de describir el curso particular de unos acontecimientos y de una concepción global de la vida (Geertz, I994).

Los practicantes construían el caso con un mínimo de información; poco importaban los motivos del consultante y la preocupación principal no era hallar la verdad en los hechos narrados -y construidos- por ese usuario ${ }^{6}$. El caso jurídico era sólo una versión de las diversas que estaban surgiendo en esa consulta in situ. En cada visita, el estudiante accedía a información nueva que suministraba el usuario, que se iba filtrando, sobre todo, a medida que el abogado encontraba el procedimiento por seguir en medio de una serie de mapas preestablecidos de situaciones típico-ideales.

\footnotetext{
6. Dentro de la terminología empleada en el contexto del Consultorio jurídico, los usuarios son las personas que acuden a consultar o quienes ya están inmersos en un proceso legal; en ese sentido, hemos preferido la denominación consultante. No obstante, se hará referencia en algunos casos a los usuarios, para traer a colación las categorías empleadas por los practicantes.
} 
En el contexto de las reuniones de los practicantes con el asesor, con frecuencia este tomaba la lectura del informe de los casos como un punto de partida para recurrir a ejemplos de casos ideales, con el propósito de encarar las situaciones planteadas por los usuarios. Sus preguntas permitían saltar de la primera traducción del hecho narrado por el consultante -operación que efectuaba el practicante- al plano de la ley, en procura de mantener la coherencia general en ese proceso. Como bien anota Geertz (I994), lo importante en la construcción del caso por parte de los abogados es crear una versión coherente, y que esa coherencia se manifieste en las pruebas como un elemento fundamental, aunque no determinante, en el proceso de creación de los hechos.

El consultante narra su historia y está a la espera de la traducción que debe hacer el practicante; obviamente, en esa traducción hay una interpretación implícita y está presente la intención de dirigir el caso hacia la dirección que el abogado considere viable $^{7}$. El practicante discute el caso con el asesor en la búsqueda del procedimiento por seguir para iniciar o no el proceso; el hecho narrado como historia personal por el usuario del Consultorio jurídico se transforma al entrar en el diálogo de los practicantes

7. Es interesante que en el caso de la conciliación en comisarías de familia, los conciliadores -entrenados en teoría de familia desde una perspectiva psicológica-terminan promoviendo la imagen del "deber ser de una familia" y, al igual que los abogados, reconstruyen una nueva versión de los hechos narrados por los usuarios pero, en este caso, basados en la teoría de familia. Según Torres (200I), los conciliadores son los protagonistas de las audiencias de conciliación y su despliegue opaca la propia exposición de las partes implicadas. con su asesor. Allí es cuando el llamamiento del asesor a esas situaciones ideales está del lado del deber ser que caracteriza a la ley. Es evidente también que la incorporación de ese hecho a la esfera de lo jurídico -o en el intento de hacerlo, como es evidente en Fredonia, donde los consultantes "no saben lo que quieren" aunque desean llegar a una instancia de reconocimiento-, requiere de la intervención del abogado para determinar cómo puede materializarse su reclamación.

La versión narrada por el usuario, y construida visita a visita, pasa a otras instancias de interpretación dentro del grupo de abogados, en las que el caso se estereotipa con base en casos estándar ligados a procedimientos relativamente fijos, fundamentados en la fuerza del lenguaje jurídico. El "lenguaje del hecho" que surge después de la primera interpretación del practicante sobre la base de lo narrado por el usuario tiene el carácter vago y en apariencia desinteresado que enuncia Geertz (I994), mientras que 


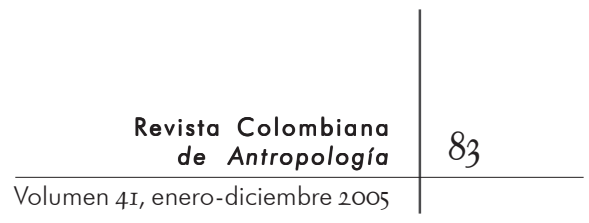

en la determinación del procedimiento legal por seguir -y durante el proceso- se acude a un lenguaje oportunista y poco metódico que busca consecuencias específicas. El lenguaje especializado -experto o técnico- puede tornarse oportunista y retórico, pues como bien concuerda Gluckman (I955: 343) con Williams -en relación con un análisis semántico del derecho-, la adopción de un lenguaje técnico es útil para prevenir equivocaciones, pero no genera significados unificados para hacer clara su aplicación en la experiencia.

El proceso de traducción hecho por el practicante contiene dos de los tres pasos en la transformación de disputas establecidos por Felstiner, Abel y Sarat (I980-8I): naming y blaming; el primero se refiere a la enunciación del conflicto o posible situación de disputa que requiere la traducción del abogado; y el segundo se relaciona con la atribución del perjuicio a otro individuo o entidad social. En este último paso hay un deseo o una petición de compensación que tiene que ver con la definición de las pretensiones que hacen los abogados. En la gran mayoría de los casos, no hay claridad sobre cómo se pueden materializar las reclamaciones y las posibles compensaciones, más aún cuando este proceso depende del curso de los acontecimientos, en el que el motivo original se va desdibujando o va siendo retocado por acciones y sujetos que entran en la disputa.

La traducción del abogado se relaciona también con uno de los procesos de transformación de disputas enunciado por Mather e Yngvesson (I980-8I): narrowing, en el que a determinadas situaciones se imponen categorías convencionales establecidas, lo cual permite manejar el caso jurídico mediante procedimientos convencionales también. Los autores hablan de la manipulación de las definiciones para conseguir fines particulares, siendo este el principal factor para restringir el conflicto o su espectro a quienes entienden, usan o actúan en nombre de ese lenguaje especializado, propio de un saber experto. Y ahí está, precisamente, el fundamento de la traducción que hace el abogado, ya que él necesita transformar las definiciones de una disputa para hacerlas susceptibles de una acción legal, en la que pueda actuar de acuerdo con una formación -entrenamiento- y un conocimiento que le permitan construir cadenas de hechos.

La dilación excesiva de los casos llevados en el Consultorio jurídico podría entenderse como el resultado de la inflexibilidad de los procedimientos y normas que impiden llegar a la toma 
de decisiones. Esta es sólo una lectura muy inicial, ya que es evidente que en relación con procedimientos y normas sí existe esa flexibilidad e improvisación; en el caso de los primeros, siempre se encuentran caminos, pese a la rigidez de los esquemas estándar; y en el de las normas, siempre hay acuerdos informales entre funcionarios -por ejemplo- para dar giros insospechados a las disputas. Esa improvisación de los estándares, en teoría rígidos, es una característica del derecho como disciplina centrada en el mundo de la experiencia que, no obstante, tiene la pretensión de presentarse como algo puramente lógico (Falk Moore, 1978). Como bien afirma esta autora, la vaguedad y los conflictos entre principios, su multiplicidad, la combinación de los mismos -precisos e imprecisos- dan al derecho la cualidad y flexibilidad que facilitan su trabajo y permiten su aplicación a diversas contingencias en torno a los asuntos humanos. A lo anterior se suma otra característica del derecho, identificada por Geertz (1994) y relacionada con su capacidad para poner cosas particulares en un marco general y hacer parecer que las normas para esa organización específica son inherentes a la esencia de su carácter general.

Cuando el asesor propone a los estudiantes la solución de situaciones ideales con el propósito de que encuentren la respuesta adecuada que se enmarque dentro de las normas, ideales también, sabe que la respuesta no se dará de esa manera en el caso narrado por el consultante. El abogado necesita de la confrontación permanente de sus conocimientos legales, que se actualizan constantemente, y deja de lado-para ponerlo en un plano más íntimo en lo que podríamos llamar una especie de transcripción privada- lo que los casos le dicen en relación con un contexto particular o una situación específica. Por esta razón, algunos practicantes se mostraban más interesados en casos que, de resolverse, pudieran empezar a ser considerados emblemáticos den-

8. En el Consultorio no se tramitan restituciones de bienes por activo, contestación de demandas, contenciosos de menor o mayor cuantía, laborales especiales y constituciones de parte civil en procesos penales. Tampoco se asume el trámite de defensas penales ante fiscalías, juzgados o inspecciones.

asesores en diferentes áreas- encontraban en ellos retos académicos o, en sus palabras, ejercicios académicos interesantes. tro de su círculo profesional; de igual manera, era frecuente que se siguiera adelante con casos que no debían ser cubiertos por el Consultorio jurídico ${ }^{8}$, en la medida en que los estudiantes -muchos aconsejados por sus 


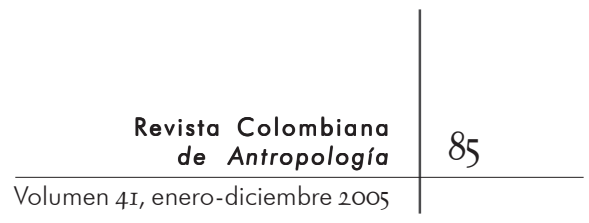

La confrontación académica en las reuniones de los practicantes puede entenderse como una forma de evaluar los conocimientos adquiridos por los estudiantes, pese a que por medio de esas situaciones estereotipadas les sea difícil actuar, sobre todo a los practicantes que hasta ahora se enfrentan a la práctica en sí, a la resolución de casos y a la construcción de los mismos en el mundo real, donde en primera instancia deben aprender a conjugar el lenguaje propio del derecho con los códigos culturales que se manifiestan en el lenguaje coloquial. Esto nos lleva a cuestionar la concepción del derecho como un sistema independiente, separado, que defiende su integridad frente a descuidos conceptuales y morales de la vida cotidiana (Geertz, I994). En uno de los casos presenciados, el asesor preguntó a la estudiante si creía en su cliente, y ella dudó, lo que le permitió a este reafirmar la idea de que lo importante es construir una versión de los hechos -una cadena coherente de hechos- en la que la versión de la otra parte pierda validez en cuanto se puedan hallar contradicciones que ratifiquen la coherencia de la propia estructuración de los hechos. Aquí lo más interesante es que la imaginación -creaciónde esa realidad por medio de la intervención del derecho trae implícita una creación de sujetos particulares, proceso que va a la par de la creación de los propios hechos.

La queja por la falta de concreción y por las incoherencias en las informaciones que los practicantes daban a los usuarios era constante, sumada a la ineficacia de las herramientas desarrolladas por el Consultorio jurídico para registrar los datos de los consultantes. Con cierta frecuencia también, los practicantes suministraban una información a los usuarios que después no reportaban en sus informes, o viceversa. Esas inconsistencias y contradicciones, presentes en buena parte de los casos presenciados por el equipo de investigación, concuerda con lo establecido por García Villegas (I993) cuando asegura que la incoherencia y la falta de concreción en la argumentación de discursos como el jurídico pueden entenderse como las fuentes de su eficacia y poder discursivo. De acuerdo con él: “(...) de esta manera puede explicarse el hecho de que en ocasiones la claridad del discurso sea la estrategia discursiva menos recomendable" (García Villegas, I993: 2I).

En ninguno de los espacios cubiertos por los etnógrafos se sancionó o penalizó esa falta de claridad con los usuarios o entre los mismos practicantes, cuando unos a otros se informaban 
superficialmente de los avances de los casos. En las discusiones se hacía énfasis en su conocimiento de las normas y sus actualizaciones constantes; muchas discusiones se dieron en un plano mucho más abstracto -alejado de los casos de los consultantes de Fredonia- en el que eran contradicciones en la norma. Estas discusiones eran las más valoradas por los practicantes, y el profesor las trataba con dinamismo, lo cual tiene que ver con uno de los objetivos más importantes del derecho, como lo plantean los mismos juristas (Alchourrón y Bulygin, 1974): la eliminación de las contradicciones en las normas jurídicas en vista de su incoherencia interna y de las incompatibilidades mutuas entre muchas de ellas.

Aun cuando se habló de los motivos académicos que hacen que un practicante preste más atención y sea diligente con un caso determinado, es evidente que muchos tienen una serie de razones que les hacen concentrarse en determinados casos, $\mathrm{y}$ esto, sin duda, se relaciona con las implicaciones morales de ser el traductor de las necesidades de los usuarios. En general, esas necesidades se relacionan con el deseo de hacer uso de un derecho al reconocimiento en el que está implícita también una necesidad de disputa, con la que se pretende llegar a instancias de reconocimiento cada vez más altas. Cuando los consultantes de los casos preferenciales acudían al Consultorio, solía haber un diálogo posterior de los estudiantes con el etnógrafo, sin la presencia del usuario; allí, estos transmitían a los antropólogos la incertidumbre y el temor hacia los procedimientos adelantados. En esas conversaciones, los practicantes manifestaban sus sentimientos, emociones e intuiciones en relación con partes de los casos o fragmentos de las narraciones de los consultantes; esa transcripción privada tenía también características que se oponen al ideal del sujeto que se plantea para los abogados -y más en las arenas del litigio-. Allí, los practicantes se alejaban de las características que ellos mismos deben adoptar e implementar al final de su formación. En este punto entramos a analizar la

9. Como se dijo, el equipo de investigación siguió la labor adelantada por seis practicantes durante la fase de campo, estableciendo así una serie de jerarquías dentro del grupo. P7 y P2 cuentan con más experiencia laboral en diferentes campos, el primero entrenado como secretario en juzgados y la segunda con una hoja de vida académica destacada y con experiencia laboral en proyectos de representación pública del abogado, en la que se conjugan los elementos señalados en relación con el lenguaje y la traducción.

En el análisis de los casos, la figura de $P I^{9}$ (practicante I) 


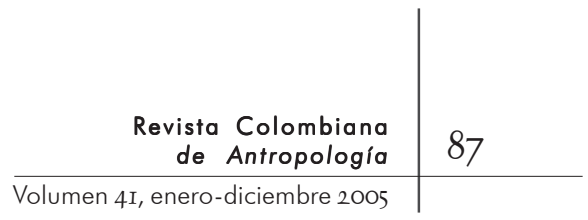

es interesante, puesto que dentro del grupo de practicantes es quien maneja el lenguaje jurídico con más propiedad delante de los usuarios; en muchos casos para no caer en contradicción, no dar explicaciones o porque desconocía la respuesta que se le solicitaba, lo cual muestra que la traducción de las expectativas del usuario a lo jurídico tiende a ser un proceso incompleto. Valiéndose del lenguaje técnico entra y sale del caso personal del consultante con la idea en mente de llegar a la instancia de decisión en la que la respuesta sea favorable en relación con el caso que él mismo ha inventado, y eso a la postre ratificaba su jerarquía frente a los otros practicantes -sólo para darle coherencia al caso de $P I$, pero esto es aplicable a cualquier contienda jurídica-. Cuando los otros practicantes hablaban de $P_{I}$ como el único que estaba despertando la malicia del abogado, se referían a su habilidad para cambiar de lenguaje de acuerdo con las circunstancias que se presentan a medida que el caso avanza. Esa, sin duda, es la parte oportunista del lenguaje jurídico de la que habla Geertz (I994). Un reflejo de esto es, justamente, el asesor de los practicantes, quien logra ejemplificar conceptos, procedimientos y casos jurídicos con una simplicidad asombrosa pero fundamentada en una percepción aguda de su interlocutor. En esta misma dirección, el análisis puede desembocar en lo establecido por Foucault (1983) cuando afirma que saber y poder no son conceptos excluyentes sino que, por el contrario, el saber es poder en la medida en que el conocimiento es una relación estratégica en la que el hombre está situado, lo que define el alcance -el efecto- de ese mismo conocimiento.

Dentro del grupo de estudiantes, $P_{I}$ y $P_{2}$ van más avanzados en este entrenamiento; son ellos quienes actúan con autoridad frente a los usuarios, hacen las preguntas claves, no olvidan los datos, llevan mejores registros escritos, controlan la conversación

$\varangle$ investigación jurídica. P3 y P4 también tienen experiencia laboral, cuentan con una hoja académica normal y detentan cierta autoridad frente a P5 y $P 6$, al llevar un semestre más en la práctica rural. En cuanto a P5 y P6, mostraban gran confianza -sobre todo durante los primeros desplazamientos- en los conceptos emitidos por P1 y P2, al punto de tenerles una admiración personal que fue comentada con los etnógrafos. Estas jerarquías se afianzaban en el trato recibido por parte del profesor-asesor, quien parecía más pendiente de los pasos dados por $P 5$ y $P 6$ en los casos que ellos tenían asignados. Para $P 2$, por ejemplo, la gran cualidad de P1, aparte de "vestir" como abogado, hablar como abogado, ser el mayor de todos y tener una facilidad de expresión impresionante, radicaba en que más que su formación académica como abogado había sido formado en "la malicia" de la profesión en los espacios, en las arenas de combate del ser abogado: juzgados, fiscalías, etcétera. 
y, con un par de palabras, como es el ideal (Robert, 2002 [I929]), pueden recordar de qué se trata y en qué punto va todo el proceso. La autoridad que detentan no les permite ser complacientes pero, a diferencia de $P_{I}, P_{2}$ consigue un equilibrio entre ser convincente sin seducir demasiado, porque $P_{I}$ se excede en sus promesas ya que parece más interesado en conseguir clientes para cuando sea abogado titulado. Por el contrario, $P_{4}, P_{5}$ y $P 6$ olvidan detalles fundamentales de los casos, preguntan información ya aclarada por el usuario y dudan de los procedimientos por seguir.

Como requisito para iniciar y mantener la consulta bajo su control, $P_{5}$ y $P 6$ no han preestablecido con claridad las preguntas básicas ni su orden, ni muestran la misma autoridad frente a los usuarios de $P_{I}, P_{2}$ y $P_{3}$, quienes en ocasiones improvisan en el orden y estructura de las preguntas obligatorias sin dejar de obtener la información deseada. P5 y P6 no "saben imponerse" a los consultantes, les permiten que prolonguen sus relatos y no logran discernir con rapidez si en medio de la información recibida hay un caso o no. El resto de sus compañeros penaliza esta actitud en las reuniones del grupo, pues los que están en las dos categorías superiores en lugar de mantener un patrón diferente de expectativa o trato para cada consultante, han empezado a desarrollar un juego de fachadas (Goffman, I959) por medio del cual movilizan experiencias estereotipadas de casos y procedimientos anteriores para ir clasificando los nuevos datos.

$P_{I}, P_{2}$ y $P_{3}$ explican conceptos y procedimientos en un lenguaje más familiar para los consultantes, mientras no se vean obligados a escudarse en él para evitar caer en contradicción o en las famosas lagunas de la ley (Bourdieu, 2002 [1989]; Alchourrón y Bulygin, 1974), que se discuten en los diálogos privados con el asesor. Ellos hacen dramatizaciones a usuarios analfabetas con el fin de enseñarles a solicitar recibidos y firmas en notarías, juzgados y demás oficinas. Se toman el tiempo para dibujar los linderos de las tierras en pleito y también redactan cartas en un lenguaje jurídico estricto, para que los consultantes cumplan de la manera más simple con el trámite.

Si se hace una lectura superficial y acudiendo a un estereotipo, podría decirse que el abogado es el sujeto que sólo puede hablar en el lenguaje rebuscado del derecho (Robert, 2002 [1929]) y es muy rígido a la hora de cumplir con ciertos procedimientos. 


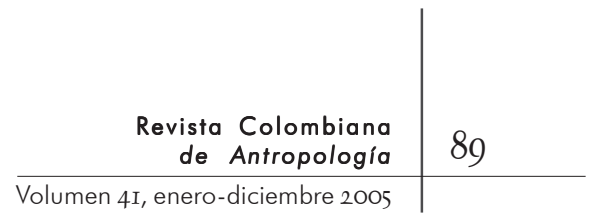

De hecho, podría decirse que el lenguaje especializado margina a quienes no pueden acceder a él (Macía, 2003) ${ }^{10}$, pero también es preciso entenderlo como un elemento de la fachada que construye el abogado, y que sólo es efectivo en determinadas cir- IO. Es interesante que la autora (Macía, 2003) cunstancias. En realidad, el abo- anote que en el lenguaje técnico existe un ingrecunstancias. En realidad, el abo- lo convierte, en el sistema jurídico cogado ideal es un sujeto claro, lombiano de tradición continental europea, en un elocuente, conciso, concreto, punto de unión entre la realidad moderna y la vivaz, recursivo, persuasivo, rá- tradición. Esta idea es fundamental a la hora de entender espacios como un consultorio jurídico pido en el contexto de la pugna de sistemas ideológicos un vocabulario rico, buen con- más amplios, cuestión que sólo se indica en este versador, convincente y culto. artículo pero que abre caminos interesantes de El practicante debe construir el

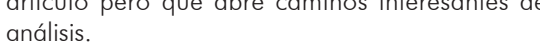
papel personal del abogado, debe saber hablar de todos los asuntos porque detenta una especie de conocimiento enciclopédico que da cuenta de una memoria eficaz y ejercitada. La preocupación por los datos curiosos revela otra característica de su profesión: la de ser experto en las sutilezas capciosas de las cuestiones jurídicas. La laboriosidad es otra cualidad que enorgullece a los abogados: se empeñan en demostrar en público que su tiempo es oro, que no pueden permitirse oír una historia de vida completa cuando hay cientos de necesitados esperando por ellos, aunque, en realidad, están a la caza de datos concretos que agilicen su labor y les permitan asumir casos con posibilidad de éxito.

$P_{I}$ cumple ágilmente con tres pasos fundamentales de la construcción del caso jurídico: I) evalúa las posibilidades de éxito del proceso (Felstiner Abel y Sarat, 1980-8I); 2) evoca las decisiones judiciales en casos análogos; y 3 ) hace una formulación normativa de las consideraciones y peticiones que deberá hacer al usuario (Robert, 2002 [I929]). La habilidad de PI contrasta con las dificultades de $P_{5}$ y $P 6$, quienes siempre se remiten a hojas de procedimientos estándar para traducir e iniciar un caso, mostrándose nerviosos e inseguros de su propia capacidad de improvisación, lo que los usuarios interpretan como falta de preparación y conocimiento. El asunto es que no debe notarse que se está improvisando, se debe dar la impresión de que la representación es resultado de una preparación concienzuda del caso o fruto de la experiencia y talento del abogado (Robert, 2002 [I929]). Posteriormente, el paso del lenguaje del hecho al plano de la decisión pondrá a prueba la capacidad del abogado de mantener la coherencia del proceso. 
PI es quien más se acerca al perfil del abogado litigante: un sujeto imaginativo que sabe administrar su poder simbólico, entendido como un poder de construcción de la realidad en el que hay una homogeneización de tiempo, espacio y lugar, que le permiten hacer ver y hacer creer (Bourdieu, 2002 [1989]). En los casos en que intervino -y no necesariamente en los que estaban a su cargo- lograba envolver a los usuarios en un ritmo vertiginoso, eufórico, combinando conceptos y términos jurídicos con frases de apoyo moral, solidaridad y reconocimiento de la situación vivida por el consultante. Así lograba la satisfacción inmediata de los usuarios, convenciéndolos de los procedimientos por seguir; tal capacidad de persuasión la usaba también para convencer a sus compañeros y al asesor de continuar con casos que por jurisdicción, entre otras razones, no podían ser llevados pero que podrían constituirse en un objeto de controversia, fruto de un primer choque con la estructura de percepción y apreciación de los conflictos del abogado (Bourdieu, 2002 [1989]). Por ese mismo choque, hechos polémicos se constituyen en un material idóneo para ser transformado mediante la construcción jurídica.

La representación en público del abogado sustenta el proceso de creación de la verdad jurídica, ya que como afirma Kant de Lima $^{11}$, esta se manifiesta como si fuera una especie de revelación que le permite al abogado evadir la responsabilidad de los hechos que él mismo crea. El

II. Conferencia sobre "Estado de direito, pluralismo jurídico e práticas institucionais". Seminario $\bigcirc$ Estado brasileiro e políticas da diferença. I2 de mayo de 2004. Escola do Ministério Público da União. II-I3 de mayo. Brasilia. canon jurídico es un reservorio de autoridad que garantiza la autoridad de los actos jurídicos singulares; el abogado adopta una posición profética al ser lector de esos textos canónicos y disimula así el proceso de creación jurídica (Bourdieu, 2002 [1989]) en el que, en el primer momento, se calculan y sopesan las consecuencias de la obediencia y la transgresión de la regla. Los abogados llegan a crear versiones tan complejas de la realidad que inciden en la pérdida de identidad momentánea de los clientes, quienes no logran reconocerse en esa configuración de hechos y sujetos inventados en la exégesis jurídica. De ahí la célebre historia del cliente que después de oír la exposición de su abogado en una reconstrucción de los hechos de su historia de vida, exclamó conmovido: "Ah, yo no sabía que había sido tan feliz" (Robert, 2002 [I929]); o cuando en medio de procesos simulados, un consultante de Fredonia, envuelto en un 


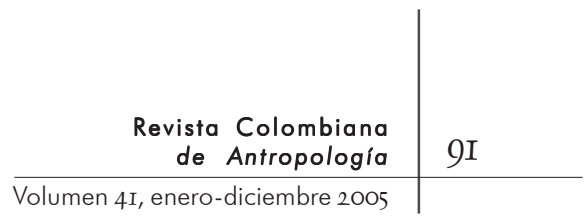

proceso de reducción de cuota alimentaria, dijo que ya no sabía quién era entre tantas mentiras inventadas por los abogados de parte y parte. Entre tanto, los practicantes aprenden la lógica de su oficio y demuestran que esa es su preocupación fundamental con frases como la pronunciada por $\mathrm{P}_{4}$ en una reunión de los practicantes: "Yo no le veo nada de difícil a ese caso, es cortar y pegar: iiipura jurisprudencia!!!”.

Sin embargo, según los parámetros de los abogados, la categoría de practicante ocupa uno de los rangos más bajos en las escalas de ascenso de la profesión. Robert (2002 [1929]) anota que la práctica jurídica implica un esfuerzo sin provecho a no ser de manera hipotética, indirecta y distante: hay desgaste y falta de reconocimiento del cliente, porque este no siente consideración por un abogado al que no pagó honorarios. Los practicantes sienten que están dando algo de sí que no es recompensado, pero no pueden aceptar otra compensación que no sea la de cumplir con un requisito para graduarse o llevar casos que se presenten como “ejercicios académicos interesantes". El hecho de que el practicante imprima algo de sí en lo que da también le crea una serie de paradojas morales y, además, debe asumir los costos personales de su posición pública como traductor, lo cual implica la contención de emociones y sentimientos. Sin embargo, los practicantes deben hacer esfuerzos y ciertos sacrificios para mantener una misma línea emocional, porque así como deben cumplir con la función de mantener el control sobre hechos, procedimientos y clientes, deben controlarse a sí mismos (Felstiner, Abel y Sarat, I980-8I). En el contexto de las reuniones, por ejemplo, el asesor trata de sacar a los practicantes del dilema de creer que lo dicho por los consultantes es un paso necesario para creer en la propia representación. Procura evitarles el sentimiento de alienación y frustración; los increpa a pensar que lo importante no es encontrar la verdad o estar seguros de lo que dicen los consultantes, porque lo fundamental es creer en la puesta en escena de la versión de los hechos creados, que deben ser configurados idealmente para no dejar lugar a las dudas. 


\section{LA ELABORACIÓN DE UNA HISTORIA, UN CASO PERSONAL}

\lfloor A CONSTRUCCIÓN DEL CASO POR PARTE DE LOS USUARIOS DEPENDE DE que entre el practicante y el usuario se establezca una relación - de confianza, pues, sin duda, esta confianza se toma visita a visita y podría decirse que es algo circunstancial. Si el practicante asignado tiene encuentros frecuentes con el consultante esto redunda en la prolongación del lazo de confianza, pero si los encuentros son esporádicos este tiende a perder lo conseguido en el encuentro anterior y comienza a buscar otros conceptos con abogados del municipio o en una red de solidaridad que se despliega en toda la localidad.

La mayoría de los consultantes acuden por recomendación de personas de la región que aconsejan la intervención de los practicantes, puesto que muchas de ellas han logrado ganar alguna batalla jurídica acudiendo a este servicio público. Esto tiene que ver con la pretensión de acceder a una instancia de reconocimiento en la que se ratifica ese derecho, idea tomada de Cardoso de Oliveira (2002), quien asegura que el derecho al reconocimiento está ligado a un proceso en el que originalmente se presenta indignación moral. El asunto es que ese derecho al reconocimiento puede definirse como una obligación moral y, por eso mismo, no tendría sentido que se convirtiese en un derecho legal que debe garantizar el sistema judicial. De otra parte, como señala el mismo autor, si se está hablando de una sociedad jerarquizada, la promesa de un tratamiento uniforme en el plano de los derechos es inútil porque provocaría más desigualdad que aceptación en otros contextos. Y es lo que ocurre en el Consultorio jurídico de Fredonia, porque aun cuando la existencia de ese espacio parte de esa pretensión universalista de que todos los ciudadanos tengan acceso a lo jurídico "en igualdad de condiciones", para los consultantes llegar a esa instancia implica entrar en un espacio de reconocimiento en el que, en el fondo, se busca desafiar ciertas jerarquías que existen en la realidad social. Esto sin contar con la transformación de las disputas en el curso de los procesos y la modificación constante de las expectativas de los usuarios. Lo que se quiere decir es que los actores pueden apelar indistintamente a cualidades de personaje social -perteneciente a una comunidad definida- e individuo para, entre otras cosas, ser reconocidos en su identidad social. Hay situaciones en las que 


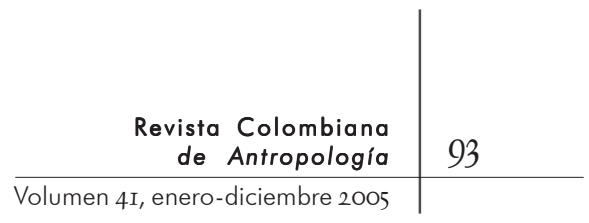

se reclama singularidad pese a que el propósito sea invertir la jerarquía social -aunque sólo sea momentáneamente-; sin embargo, en otros casos, recurrir al Consultorio jurídico sirve para ratificar valores jerárquicos y eso no excluye la experiencia de reclamar determinados derechos individuales ${ }^{12}$. Este es otro campo que merece ser explorado y que nos lleva a pensar en el Consultorio jurídico de Fredonia como un lugar donde es posible ver cuestiones que refieren a un orden jerárquico característico de una región campesina, en la que opera una ideología ligada a una estructuI2. En este punto me distancio de lo dicho por Macía (2003) en su trabajo sobre un consultorio jurídico popular en Bogotá, puesto que estos espacios jurídicos no remiten sólo a marginación, exclusión y violencia, por un lado, y a un posible empoderamiento, por otro. En dicho escenario están en juego las jerarquías e identidades, y poner la relación abogado-consultante en términos del elemento que subordina y el subordinado simplifica el proceso de representación -y negociaciónque se da en el consultorio jurídico y que habla de las estrategias que se adoptan de parte y parte, pese a que no se pueda hablar de la efectividad duradera de las mismas. ra agraria específica. Por ello, es plausible decir que en el contexto de la consulta jurídica coexisten valores pertenecientes al holismo y al individualismo.

La confianza que deposita el usuario en el practicante depende en gran medida de la reclamación que este haga, lo que nos lleva de nuevo al proceso de traducción hecho por el abogado. Los consultantes asumen como actos de desconsideración de parte de los practicantes las respuestas insatisfactorias que reciben en cada desplazamiento -la ausencia de razones, el olvido de documentos, las citas y llamadas incumplidas, además de los trámites retrasados o las devoluciones en muchos de los procedimientos-, lo que está en relación directa con los intereses que tienen en la resolución de su conflicto. Esto remite a la historia detrás de ese conflicto y a las circunstancias que se van sumando durante la construcción del caso in situ. Para quienes reclaman, el tiempo de duración del conflicto disloca todos los demás aspectos cotidianos a un plano secundario, porque se desarrolla en una temporalidad particular que contrasta con la vida cotidiana e implica un fuerte desgaste emocional (Bevilaqua, 2002).

A pesar de que la información recopilada durante el trabajo de campo corresponde a problemas jurídicos y procedimientos diferentes, es posible identificar tres rasgos fundamentales en la construcción de la historia personal: r) la historia se va construyendo a la par que se evaluan los efectos de la traducción del practicante; 2) la construcción del caso suele remitir a una narración cronológica de los hechos, que hace parte de un formato 
de historia de vida más amplio; y 3) el diálogo con el abogado está ligado a un performance o puesta en escena que sustenta la historia personal. La primera característica remite a un caso personal que se construye a cuentagotas; por lo general son personas que no tienen claridad sobre lo que van a reclamar, no tienen claras sus pretensiones, pese a que intuyan que pueden usufructuar algo por medio de la intervención jurídica. Se presentan por recomendación de individuos que estuvieron en situaciones de vida similares y llegan con una actitud poco asertiva; son mucho más pacientes frente a las inconsistencias, inasistencias, descuidos y demoras de los practicantes; es muy probable que también sean aconsejados a responder las preguntas que les hacen los estudiantes sin salirse demasiado del esquema preguntarespuesta, evitando así contar sucesos que puedan ser malinterpretados por los practicantes y les impidan llevar el caso. Esta posición resulta muy estratégica, porque para los abogados es mucho más cómodo -como ellos mismos aseguran- tratar casos en los que las personas les permitan ser concretos, contesten sus preguntas sin extenderse demasiado y, además, cumplan con llevar la documentación solicitada.

Veamos el caso de $C$., quien trabajó como empleada doméstica en una casa en la parte urbana del municipio entre abril de I999 y enero de 2003. Ella renunció alegando que estaba cansada, enferma y quería dedicarse al cuidado de sus hijos. Cuando acudió al consultorio ya había hecho una petición ante la oficina de trabajo de la localidad, aconsejada por otras personas, en la que solicitó la revisión de su liquidación. Ante la negativa de sus empleadores a pagarle \$347 mil, según lo establecido en la oficina de trabajo, decidió ir al Consultorio jurídico. El practicante, junto con su asesor en materia laboral, hizo una liquidación en la que se tuvieron en cuenta las cesantías no pagadas, los intereses sobre las cesantías y el reajuste salarial de los años trabajados. El monto ascendía a siete millones de pesos, y dado que los recibos de pago que tenía $C$. sólo correspondían a un mes por cada año trabajado, el caso se volcó a la consecución de testigos. Entre tanto, $C$. intercambiaba insultos con sus antiguos empleadores, cuando el practicante le dijo que hablara con ellos para intentar conciliar; intento que él mismo hizo recibiendo respuestas violentas de la otra parte.

En situaciones como la de $C$., el primer estímulo fue tratar de aprovechar el hecho de que no fue bien liquidada -según lo exigido 


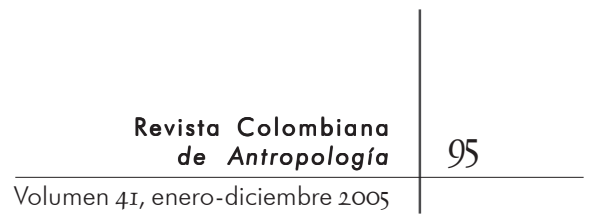

por la ley- para conseguir un dinero adicional de sus patrones; aquí, la intervención de las redes de información fue clave, pues así ella pudo hacer una primera reclamación en la oficina de trabajo de Fredonia. Al obtener una respuesta agresiva de parte de sus empleadores, decidió avanzar a una instancia mayor de reconocimiento: el Consultorio jurídico rural -por lo menos así parecen percibirlo muchas de las personas que acuden a él-. Aquí ya es evidente un cambio en la disputa ${ }^{13}$, porque el problema de la indemnización pasó a segundo plano y se trajeron a colación gestos de desconsideración de los patrones en relación con su enfermedad, información de la que se valió el practicante para añadir pruebas al caso, ya que los empleadores debían pagar los gastos de la enfermedad pues en ese enton-

I3. Los practicantes asumen la transformación del conflicto de los usuarios como un cambio en el procedimiento por seguir, desconociendo las implicaciones morales que para los consultantes tienen los nuevos rumbos que toma su caso perces ella aún trabajaba para sonal.

ellos. Esto obligó a la consultante a buscar fórmulas y a procurar los conceptos de médicos, entre otras cosas.

A medida que el proceso iba avanzando, la actitud de la consultante cambió radicalmente: era mucho más agresiva y a pesar de que mantuvo su manera de construir el caso, guiada por las preguntas e indicaciones del practicante, fue dejando ver las razones de orden moral que la hacían continuar en la disputa. Fuera del contexto del Consultorio jurídico el intercambio de insultos se recrudecía, pero dentro se traía a colación la enfermedad como marco general de la pugna. Aquí se evidencia la tercera característica de la construcción del caso por parte del consultante -que se amplía más adelante-, ya que en la puesta en escena durante la consulta es constante la presentación de la pobreza y la enfermedad como trasfondos para la elaboración de los hechos. Como se dijo, la usuaria empezó a dejar ver cómo los insultos recibidos y, sobre todo, la negación de parte de sus antiguos empleadores de que ella tuviera la posibilidad de ganar una demanda, y, más aún, la negación de que ella fuera a recibir dinero como indemnización, la impulsaban a seguir con el proceso hasta las últimas consecuencias.

Cuando el practicante le informó la suma por la que podía ser indemnizada ella se sintió reconocida, a pesar de que después se le dijo que debía negociar esa suma, porque era muy difícil que personas de un estrato socioeconómico como el de sus 
empleadores le pudieran pagar siete millones de pesos. Su respuesta fue contundente, puesto que dijo que para ella bastaba con que le pagaran la suma que se había establecido en la conciliación en la oficina de trabajo (\$347 mil).

En el caso de $R .{ }^{14}$, al igual que en el de $C$., más que el pago

I4. R. se desempeñaba como mayordomo en una finca de la región; dentro del grupo de practicantes su caso era conocido como el de "los veintisiete marranos". Renunció alegando que su patrón no le estaba suministrando lo necesario para el funcionamiento de la finca. Aparte de la deuda en salarios -veinte meses según él-y prestaciones sociales, los ochenta cerdos a su cuidado estaban muriéndose de hambre porque no había cómo comprarles el alimento. Cuando R. acudió a la inspección de policía ya habían muerto veintisiete cerdos; el inspector hizo el acta de la visita y lo autorizó a vender algunos cerdos para darle alimento a los otros, pero por recomendación del dueño del almacén de productos agropecuarios no lo hizo y decidió que "lo mejor" era dejar morir los cerdos para no tener más problemas. Pese a que la esposa del dueño atestiguó la muerte de los cerdos en una de sus visitas, la situación continuaba y aunque $R$. ya había renunciado, permanecía en la finca a la espera del pago de lo adeudado. Además, se quejaba de una epidemia de moscas que estaba afectando a sus hijos y traía a colación también la muerte de una de las yeguas de la finca por falta de alimento.

fuera de este contexto especial.

Lo anterior se relaciona con lo que Falk Moore (1978) dice sobre el derecho primitivo, y es coherente con el análisis de la construcción de los hechos por parte del usuario, pues la autora llama la atención sobre cómo la expansión de la disputa se da en determinadas unidades sociales y opera en niveles estructurales específicos. En el caso de los conflictos analizados, y principalmente en los relacionados con el primer rasgo de la construcción del caso personal, se desafían posiciones estructurales correspondientes a las jerarquías sociales más marcadas en el contexto cultural de la zona. Digamos que la red local de consejos y sus ramificaciones funcionan en un mismo nivel jerárquico. Trabajadores a destajo recurren al Consultorio porque otros trabajadores de menor rango acudieron a esa misma instancia -con o sin éxito en sus respectivos procesos-. Las empleadas domésticas llegan por recomendación de sus vecinas de 


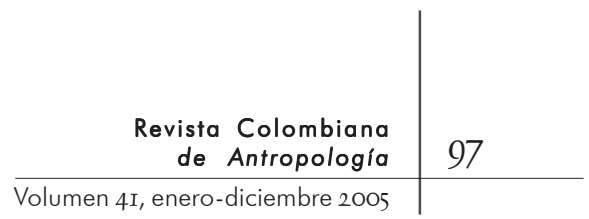

vereda, muchas de las cuales también se han empleado en el servicio doméstico alguna vez, estrategia común en la región que permite reunir ingresos para el grupo familiar. Esto responde a lo que la misma Falk Moore (I978) anota en relación con las batallas legales, en la medida en que involucran a individuos específicos que sirven a los grupos a los que pertenecen para marcar los antagonismos característicos de la relación entre ellos.

La exploración en estos conflictos permitiría extrapolar conclusiones en relación con la complejidad de dichas relaciones en la región, que remiten al choque de dos formas de representación -centradas en un saber especializado y en lógicas locales-, pero que están respaldadas en ideologías diferentes -individualista y holista o jerárquica-. Como se dijo, lo relativo a sistemas ideológicos no se trabaja en este artículo; sin embargo, hay que decir que ganar y recibir una retribución moral, desafiar la autoridad de quienes tradicionalmente la han detentado, es un estímulo para sentar ese precedente ante la incertidumbre de que el caso llegue a término y de que la decisión sea satisfactoria. Por supuesto, aquí se debe conceder gran importancia a lo que se ha denominado cadena local de consejos, ya que allí individuos en posiciones estructurales semejantes van acumulando reclamaciones sociales -que se revisten de un carácter moraly manifiestan su solidaridad mediante la consecución de alternativas jurídicas para llegar a un plano de reconocimiento e, idealmente, de reivindicación; una de estas alternativas es, precisamente, el Consultorio jurídico.

El segundo rasgo de la construcción de los hechos por parte del usuario se relaciona con los consultantes que tienen afán de contar su historia de vida en orden cronológico. En esos casos se narran aspectos esenciales del ciclo vital, que se ligan al relato del problema jurídico por resolver. Las referencias al pasado son constantes y la búsqueda de reconocimiento se orienta hacia el propio acto de narrar una historia de vida salpicada por actos que merecen aprobación social, de acuerdo con códigos valorados en el contexto cultural particular: el cumplimiento de tratos de palabra, el sacrificio para adquirir las posesiones materiales, lo dado a los hijos durante la crianza, el trabajo detrás de las mejoras de un predio, etcétera. Por lo general, estas personas son ancianos cuyos conflictos fueron resueltos por la intervención de otros sistemas de justicia -alternativos y locales- pero que luego se ven obligados a legalizar muchas de las transacciones y procedimien- 
tos y, por eso, acuden al Consultorio jurídico. Lo anterior sin desconocer la influencia e intervención de la red local de consejos, que los estimula a acudir a la ayuda de los practicantes ${ }^{15}$.

En su mayoría, esos conflictos fueron el resultado de transacciones hechas en el pasado, bajo la preeminencia de lógicas de elaboración de acuerdos y resolución de conflictos diferentes. Aquí hablamos principal-

I5. Esto contrasta con lo establecido por Torres mente de cuestiones relativas (200I) a partir de la etnografía que hizo en una comisaría de familia de Bogotá, puesto que las mujeres acudían a esta instancia cuando el conflicto pasaba el umbral de lo tolerable; así mismo, las audiencias se daban en un "contexto de urgen$\mathrm{cia}^{\prime}$. En este caso, acudir a la comisaría de familia no se relaciona con un estímulo por parte del grupo al que se pertenece, sino que surge ante una situación de emergencia y por iniciativa individual. De hecho, las mujeres entrevistadas dijeron que no denuncian a sus compañeros por retrasos en la cuota de alimentos porque ellos pueden sentirse acosados, aumentando así la gravedad del conflicto intrafamiliar. a la posesión, compra-venta y sucesión de tierras e inmuebles, divorcios y cuotas de alimentos. En estos casos, los consultantes sienten que una deuda cancelada reaparece de repente, pero junto con otros compromisos que están inscritos en lenguajes y procedimientos que no tienen nada que ver con los hechos que suscitaron esos pleitos más recientes. Los usuarios le atribuyen al trámite jurídico una dimensión moral y simbólica que está fuera de los valores asignados al espacio por los mismos abogados.

El caso de Z. sirve para ilustrar este punto. Este usuario tenía ochenta años de edad, era analfabeta y tenía problemas de memoria; acudió al Consultorio jurídico con la esperanza de legalizar una tierra que compró cuarenta y siete años atrás, y en la que vive. En cada visita narraba la historia del terreno al tiempo que iba reconstruyendo su historia familiar. Aun cuando tenía las escrituras originales, el predio no aparecía registrado ni en la oficina de instrumentos públicos ni en la de catastro municipal. Por esa razón, no podía iniciarse un proceso de pertenencia y, mucho menos, uno de sucesión, su principal preocupación. La practicante envió varias solicitudes y derechos de petición por escrito a dichas instituciones para que ayudaran a $Z$., en vista de que tenía problemas de memoria y era analfabeta. Así mismo, trató de hacer simulacros para entrenarlo en los trámites que debía hacer en las oficinas públicas, pero nadie logró convencerlo de que firmar no era perjudicial. Luego de tres meses el caso continuaba en el mismo punto; cuando la estudiante buscó una nueva alternativa, hablar con los vecinos del usuario para tratar de hacer el seguimiento del número del registro de 


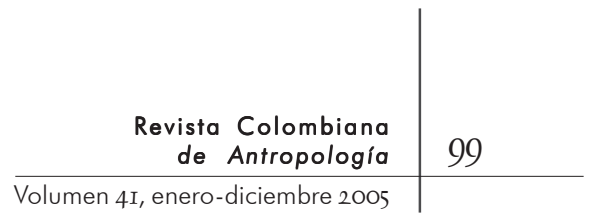

inmueble, $Z$. se negó, pues para él era inconcebible preguntarle a personas que no habían estado presentes en el momento exacto -histórico- de la transacción y que no habían conocido personalmente a su patrón.

Los espacios jurídicos están llenos de una expresión de emociones que hacen parte del juego de reconocimiento de dignidades en pugna, en lo que correspondería a una dimensión performativa -dramatización- del reconocimiento (Cardoso, 2004; Peirano, 2002). La construcción del caso personal está ligada a un performance que ocurre durante la consulta. Muchas personas acuden -en la primera visita o en un punto crucial del proceso- con esposos, esposas, hijos, familiares y amigos de confianza. Otros consultantes van con niños de brazos o en compañía de hijos pequeños que, en algún punto de la narración del caso personal, se presentan como una evidencia que realza el relato, pero que sirven también para ganar la confianza del practicante. En otras situaciones, las personas van armadas de documentos que no sólo remiten a la cuestión jurídica por resolver, sino también a los trasfondos generales de los que hemos hablado: pobreza, humildad y enfermedad. Entonces, muestran heridas, cicatrices, fórmulas médicas, exámenes, radiografías, etcétera, para ir encadenando y construyendo los hechos de su propia historia, lo que da cuenta de una necesidad de performance presente a la hora de acceder a este espacio de reconocimiento, en el que se hacen evidentes las fallas en compromisos morales entre las distintas partes involucradas en transacciones de diversa índole. Falk Moore (I978) dice que las obligaciones morales son aquellas en las que la presión de sanción social se usa para obtener un performance, mientras que en las obligaciones legales el empleo de la fuerza tiende a ser más inmediato. Esto también puede relacionarse con lo enunciado por Cardoso de Oliveira ${ }^{16}$ sobre los reclamantes persistentes, indivi- I6. Conferencia sobre "A invisibilidade do insulto duos que tienen actitudes ou como perder o juízo em juízo". Seminario 0 Estado brasileiro e políticas da diferença. I2 de incompatibles con el compor- mayo de 2004. Escola do Ministério Público Supetamiento aceptado en un tribu-

rior da União. II-I3 de mayo. Brasilia.

nal, pero cuya persistencia

tiene que ver con una expresión usada por los abogados en Estados Unidos -having her/his day in court- que, en últimas, habla de cómo una búsqueda de reconocimiento envuelve esa necesidad de performance. 
Arriba se decía que la satisfacción de esa necesidad de performance podía llegar a suprimir -por lo menos por un momento- las implicaciones que determinados estatus tienen en un contexto particular. Es como si en la dramatización los usuarios estuvieran oscilando: se paran desde su posición en la estructura, ligada al rol específico, pero buscan una reivindicación apelando a la condición de individuos con derechos. De cierta manera, podría decirse que uno de los propósitos del performance es tratar de evadir los sistemas de autoridad propios de la estructura social del lugar para ubicarse en una posición superior a la de quien pretenden procesar. No obstante, en muchos casos el proceso de disputa es tan complejo y la invención de los hechos -de parte de usuarios y abogados- tan costosa social, moral y emocionalmente, que cuando se llega a una instancia de decisión jurídica hay una especie de pérdida de la identidad. Y, de todas maneras, en los momentos de decisión judicial se evidencia con mayor fuerza la eficacia simbólica del derecho (Bourdieu, 2002 [1989]; García Villegas, I993), ya que la arbitrariedad de la construcción de los hechos se ignora en aras de la legitimación del veredicto. Cuando esto ocurre, los intereses materiales no son los principales estímulos para seguir adelante con las disputas, porque está en juego la definición y reconocimiento de los sujetos, lo que se relaciona con la restitución del honor, por ejemplo (Bevilaqua, 200I).

Esto nos lleva caso de $D$., quien había sido demandado por alimentos en Quibdó en 1984, siendo esa la primera demanda interpuesta por la madre de sus tres hijos mayores, de veinticuatro, veintidós y dieciocho años de edad. Él nunca vivió con ellos pero siempre cumplió con la obligación de enviarles dinero mensualmente, y es enfático al afirmar que el único mes en que no lo envió, situación acordada con la madre de sus hijos, fue usado como excusa para demandarlo. Además de los tres hijos en Quibdó, $D$. tiene otra hija -de veintidós años tambiénen la ciudad de Medellín, producto de una relación pasajera, y uno de quince años con su actual compañera; los tres viven juntos en el municipio de Fredonia. A mediados de 2003, se dio cuenta que el porcentaje descontado por alimentos había aumentado de $30 \%$ a $40 \%$.

El consultante tenía claro qué iba a reclamar pues ya había estado envuelto en un proceso jurídico por una demanda de alimentos interpuesta veinte años atrás y, por esa razón, acudió 


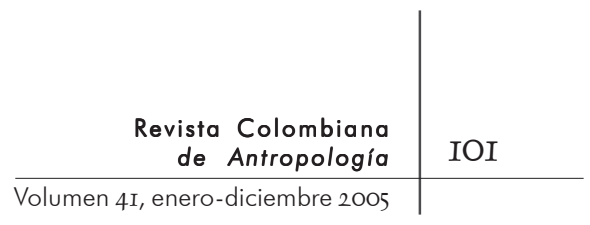

al Consultorio jurídico: buscaba la reducción de ese ıо\% en la cuota alimentaria, que le fue incrementado sin justificación alguna. Además, para él había razones morales que lo impulsaban a continuar con la disputa: el hecho de que sus hijos sólo se relacionaran con él por el interés económico, los engaños de la madre de los mismos en transacciones informales, las agresiones contra su propia imagen al ser tachado de irresponsable, incumplidor, etcétera. En este caso no se busca afirmar una superioridad moral ante una inferioridad implícita o parte del intercambio, como lo plantea Bevilaqua (2002) en el caso de los pleitos entre consumidores y proveedores; él busca recuperar una posición en una escala moral porque, justamente, ha sido rebajado durante todo el proceso y espera compensar las consecuencias de insultos sucesivos. De esta manera, se presenta la lucha por un reconocimiento de otro tipo: hay una cadena de conflictos precedentes y existe un resentimiento acumulado, fruto de una serie de actos de desconsideración anteriores; ese resentimiento puede entenderse como la reacción -el sentimiento- a una agresión intencional a la cual sobreviene la reacción de indignación moral y la búsqueda de reconocimiento (Cardoso de Oliveira, 2002, 2004) en los espacios jurídicos en los que tomó forma la disputa, pero no donde se originó.

En cierto sentido, la primera reacción del consultante fue buscar la solidaridad del abogado -y el etnógrafo-, y creyó haberla conseguido cuando el practicante le propuso que simularan una conciliación ${ }^{17}$, procedimiento que después se transformó y confundió aún más el conflicto, en la medida en que el usuario adquirió nuevas obligaciones legales que le recordaban las implicaciones morales de la primera demanda. Es interesante haber presenciado la transformación de la disputa, ya que de un principio de identificación

I7. En este procedimiento, propuesto por PI, se buscaba que la actual compañera de $D$. , con quien tiene una relación estable, lo demandara por alimentos de su hijo de quince años -el único hijo menor de edad del consultante- para lo cual era necesario hacer primero una conciliación en la que se fijara una cuota mensual -un compromiso- de parte de $D$. Al incumplir este acuerdo por dos o tres meses consecutivos se podría hacer la demanda y así intentar que el juez de Quibdó considerara la reducción de la cuota de alimentos, equivalente a $40 \%$ del salario del consultante. biente de la "comunidad de conversación” establecida durante la consulta-, lo que se podría entender como un acto de reconocimiento, el conflicto se fue transformando hasta el punto de que el usuario no lograba identificarse en los documentos y hechos elaborados por los practicantes. Se 
veía desesperado y la idea de aceptar la simulación de una demanda que sería interpuesta por su actual esposa e hijo -con los que intentó "corregir los 'errores"” cometidos en las uniones anteriores- le hacía sentir negada cualquier posibilidad de reivindicación. El problema es que este era sólo un momento más en la serie de disputas que marcaron su historia de vida. El procedimiento seguido por los practicantes lo hizo sentir vulnerable porque estaba duplicando las posibilidades de conflicto. Después de la aparición de una nueva demanda en Quibdó y de una citación que, según él, nunca recibió, pero en la que se daba por descontada una mala intención de su parte al asumirse que no había querido asistir a dicho encuentro, el consultante sintió esa pérdida de la identidad; no era el sujeto que habían construido los practicantes en aras de traducir una serie de resentimientos que él ocultó tras la enunciación de un motivo concreto: la reducción de la cuota de alimentos.

El Consultorio jurídico funciona a diferentes niveles y en el espacio de la consulta jurídica se hace evidente un choque de lógicas que implican formas diferentes de construcción del caso y de la representación. Por ello, el proceso de traducción y, sobre todo, el procedimiento jurídico, tiende a ser mucho más complejo y prolongado. La red local de consejos opera para que se acuda al Consultorio jurídico en la resolución de conflictos de diferente índole, incluso por problemas relacionados con brujería y chismes, que los practicantes rechazan rápido. Esto ocurre porque una victoria legal se repolitiza y colectiviza, y la experiencia de la disputa estimula al participante a dar pasos para ubicar su comportamiento en una posición más fuerte de llegar a presentarse otro conflicto (Felstiner, Abel y Sarat, I9808I). En esas transformaciones, algunas pugnas originalmente colectivas se hacen individuales, lo que se relaciona con las diversas ecuaciones que pueden surgir en la combinación de las particularidades relativas a las dimensiones temáticas presentes en los conflictos que llegan a una instancia jurídica -derechos, intereses y reconocimiento- (Cardoso de Oliveira, 2004).

En la comprensión de cómo crean el abogado y el consultante sus respectivos casos, sin desconocer la interrelación entre estas versiones y sus puestas en común, pueden evidenciarse las transformaciones en las disputas por las que claman autores como Felstiner, Abel y Sarat (1980-8I) y Mather e Yngvesson (I980-8I), 


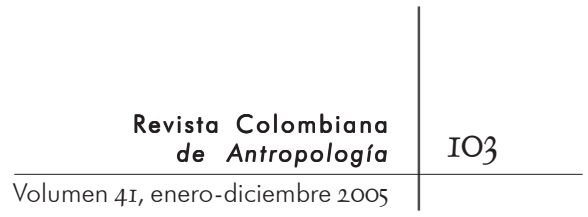

pues en esa construcción se dejan al descubierto las posiciones sociales de los individuos involucrados y los movimientos que se hacen en relación con ellas, incluso en el intento de desafiarlas. Al conocer las características de la construcción del caso personal se puede entender, por ejemplo, por qué en la transcripción y traducción que hace el abogado se asignan valores diferentes a experiencias que los consultantes consideran similares o, caso contrario, se otorgan valores similares a experiencias que los implicados consideran diferentes. Todo esto en medio de la confirmación y escrutinio hechos por los usuarios con vecinos, parientes y amigos, miembros de esa gran red local de consejos.

Aquí está la clave para entender la insatisfacción con la traducción de pretensiones o con la resolución de los conflictos, en la medida en que se desconocen o excluyen de la traducción jurídica los agentes y factores que se van incorporando al caso. En el texto de Felstiner, Abel y Sarat (I980-8I) se habla de un tercer paso en la transformación de disputas-claiming-, que se refiere a la reclamación que puede desembocar en reivindicación. Lo interesante es que esto nos lleva, precisamente, al papel del insulto moral en escenarios jurídicos, puesto que la parte afectada espera obtener de la otra algo que depende no sólo de su actuación en la situación original en la que surgió el conflicto, sino del comportamiento que vaya teniendo esa otra parte a lo largo de la disputa, pues es allí donde se acumula resentimiento ante acciones sucesivas de desconsideración (Cardoso de Oliveira, 2002). Tal como se ve en los casos de $C$. y $D$., las reclamaciones de sus protagonistas son una mezcla de sentimientos y objetivos, que van más allá del puro interés económico.

Párrafos atrás se dijo que la enfermedad, la humildad y la pobreza constituían un marco general en el que se podían ubicar los contenidos de las disputas. Pese a que en los intentos de reivindicación de $R$. y $C$., por ejemplo, esté presente el propósito de desafiar determinados estatus, en el diálogo adelantado en el contexto de la célula básica hicieron énfasis en la inferioridad y distancia frente a sus oponentes, pero esa inferioridad remite a las características enunciadas antes -pobreza, humildad, enfermedad-que pueden ser colectivizadas o individualizadas. Esto coincide en el proceso de expansión que identifican Mather e Yngvesson (1980-8I) en las transformaciones de pleitos, donde apelar al grupo - o a una condición ambigua de un 
grupo no del todo diferenciado, como podría ser el caso de la red local de consejos- ayuda a resolver problemas particulares; no obstante, ocurre también el proceso inverso, cuando un caso individual moviliza cuestiones que atañen a ciertas colectividades. No es tanto que la expansión sea un mecanismo mediante el cual emerjan nuevas reglas durante el proceso legal, lo importante es que por medio de ese proceso se desarrolla un marco en el que se incluyen nuevas categorías, participantes y aspectos por debatir. Tampoco es que el análisis de la construcción de los casos jurídico y personal de cuenta de la transformación del marco normativo convencional -institucional-, pero sí muestra las condiciones que se dan para que surjan las múltiples versiones e interpretaciones de los hechos que van creando los diversos sujetos en un contexto, en principio, jurídico.

Geertz (I994) asegura que el derecho no es una reflexión hermenéutica que pueda servir como un medio para dar sentido a cosas particulares, y parece más interesado en demostrar que es conocimiento local sin un único origen pero que construye la vida social y no la refleja. Discrepando con él de cierta manera, podría decirse que en la práctica social el derecho tiene una función importantísima que permite una construcción de sentido -en cuestiones particulares- a quienes creen que allí se pueden traducir y materializar sus demandas, necesidades y disputas. Este proceso consiste en una traducción que se establece gracias a la intervención del abogado -y a su propia representación- pero que, en realidad, opera como un proceso colectivo y dialéctico de construcción de sentido, pese a que surjan sentidos diferentes para cada sujeto involucrado en ese diálogo. Como bien afirma García Villegas (1993: 3): “(...) el hecho de que las normas logren eficacia por medio de las representaciones que ellas crean en los individuos, hace del derecho un instrumento social necesariamente ligado al mundo de lo simbólico y con él al mundo de lo político. Así, el derecho es portador de una o varias dimensiones a la vez -la jurídica, la coercitiva, la simbólica, etc.”. En este sentido, espacios como el Consultorio jurídico pueden ser mecanismos que posibilitan la efectividad de derechos y, a largo plazo, pueden llegar a generar discursos de autoentendimiento. Sin embargo, es importante decir que mientras cuestiones como la práctica jurídica sean vistas -o quieran ser vistas-exclusivamente en términos de la resolución de problemas 


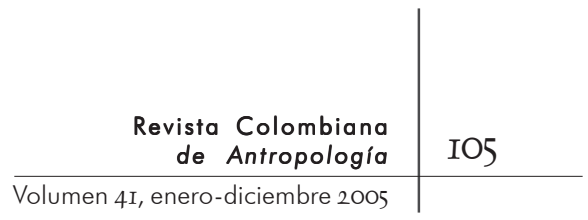

imaginarios -ejercicios académicos ideales-, el derecho seguirá siendo un mecanismo imposibilitado para comprender valores sociales (Geertz, 1994) y se limitará a contribuir al sistema legal total en la interiorización de jerarquías, en la interiorización y “naturalización” de la idea de desigualdad ${ }^{18}$.

I8. Esta idea se retomó de lo dicho por Kant de Lima en relación con el sistema judicial brasileño en la conferencia "Estado de direito, pluralismo jurídico e práticas institucionais". Seminario $\bigcirc \mathrm{Es}-$ tado brasileiro e políticas da diferença. I2 de mayo de 2004. Escola do Ministério Público Superior da União. II-I3 de mayo. Brasilia.

\section{BiBLIOGRAFíA}

Alchourrón, C. y E. Bulygin. 1974. Introducción a la metodología de las ciencias jurídicas y sociales. Astrea. Buenos Aires.

Bevilaqua, Ciméa. 2002. "O consumidor e seus direitos: um estudo sobre conflitos no mercado de consumo". Tesis presentada a la facultad de filosofía, letras y ciencias humanas de la Universidade de São Paulo para obtener el título de doctor en antropología social.

. 200I. "Notas sobre a forma e razão dos conflitos no mercado de consumo". Sociedade e Estado (dádiva e solidaridades urbanas). XVI (I-2).

Bourdieu, Pierre. 2002 [1989]. O poder simbólico. Editora Bertrand. Rio de Janeiro.

Cardoso de Oliveira, Luis Roberto. 2004. "Honra, dignidade e reciprocidade". En P. H Martins y B. F. Nunes (orgs.). A nova ordem social: perspectivas da solidaridade contemporánea. Vozes. Rio de Janeiro.

- 2002. Direito legal e insulto moral: dilemas da cidadania no Brasil, Québec e EUA. Relume Dumará. Rio de Janeiro.

Cardoso de Oliveira, Roberto. 2000. O trabalho do antropólogo. Editora Unesp. São Paulo.

FALK MoORe, SALLY. 1978. Law as process. An anthropological approach. Routledge \& Keegan Paul. Londres/Boston.

Felstiner, William, Richard Abel y Austin Sarat. i980-8I. "The emergence and transformation of disputes: Naming, blaming, claiming”. Law \& Society Review. I5 (3-4).

Foucault, Michel. 1983. La verdad y las formas jurídicas. Gedisa Editorial. Madrid. 
García Villegas, Mauricio. ig93. La eficacia simbólica del derecho. Ediciones Uniandes. Bogotá.

Geertz, Clifford. 1996. La interpretación de las culturas. Gedisa Editorial. Madrid. . 1994. Conocimiento local. Ediciones Paidós. Barcelona.

Gluckman, Max. 1955. The judicial process among the Barotse of Northern Rhodesia (Zambia). Manchester University Press. Manchester.

GofFMAn, ERving. I959. The presentation of self in everyday life. Anchor Books. Nueva York.

Gudeman, Stephen y Alberto Rivera. 199o. Conversations in Colombia. The domestic economy in life and text. Cambridge University Press. Cambrigde.

Hammersley, Martin y Paul Atkinson. i994. Etnografía: métodos de investigación. Alianza Editorial. Madrid.

Jackson, Michael. 1998. Minima Ethnographica. Intersubjectivity and anthropological project. The University of Chicago Press. Chicago.

Macía Vergara, Laura. 2003. Entre la mesa y la pared. Clientes y doctores en un consultorio jurídico popular. Nuevos Estudios Socio Jurídicos. Universidad de Los Andes. Bogotá.

Mather, Lynn y Barbara Ygnvesson. I980-8I. "Language, audience and the transformation of disputes". Law \& Society Review. I5 (3-4).

Peirano, Mariza. 2002. O dito e o feito. Ensaios de antropologia dos rituais. Relume Dumará. Rio de Janeiro.

Robert, Henri. 2002 [1929]. O advogado. Martins Fontes. São Paulo.

Torres Niño, Alba Leonor. 200i. "La mediación y la familia. Conciliación de alimentos en la Comisaría I2 de familia". Tesis de grado para optar al título de antropóloga. Universidad de los Andes. Bogotá.

Recibido: 8 de agosto de 2004.

Aprobado: 30 de diciembre de 2004. 